\title{
Differential Expression of TASK Channels between Horizontal Interneurons and Pyramidal Cells of Rat Hippocampus
}

\author{
Stefano Taverna, Tatiana Tkatch, Alexia E. Metz, and Marco Martina \\ Department of Physiology, Feinberg School of Medicine, and Institute for Neuroscience, Northwestern University, Chicago, Illinois 60611
}

Among the electrophysiological properties differentiating stratum oriens horizontal interneurons from pyramidal neurons of the CA1 hippocampal subfield are the more depolarized resting potential and the higher input resistance; additionally, these interneurons are also less sensitive to ischemic damage than pyramidal cells. A differential expression of $\mathrm{pH}$-sensitive leakage potassium channels (TASK) could contribute to all of these differences. To test this hypothesis, we studied the expression and properties of TASK channels in the two cell types.

Electrophysiological recordings from acute slices showed that barium- and bupivacaine-sensitive TASK currents were detectable in pyramidal cells but not in interneurons and that extracellular acidification caused a much stronger depolarization in pyramidal cells than in interneurons. This pyramidal cell depolarization was paralleled by an increase of the input resistance, suggesting the blockade of a background conductance.

Single-cell reverse transcription-PCR experiments showed that the expression profile of TASK channels differ between the two cell types and suggested that these channels mediate an important share of the leakage current of pyramidal cells.

We suggest that the different expression of TASK channels in these cell types contribute to their electrophysiological differences and may result in cell-specific sensitivity to extracellular acidification in conditions such as epilepsy and ischemia.

Key words: KCNK; potassium; leakage; patch clamp; PCR; anesthetics

\section{Introduction}

GABAergic interneurons and glutamatergic pyramidal cells of the hippocampus differ in the sets of voltage- and ligand-gated ion channels they express (Geiger et al., 1995; Martina and Jonas 1997; Sperk et al., 1997; Martina et al., 1998). Moreover, most interneurons have a more depolarized resting potential and higher input resistance than pyramidal cells (Morin et al., 1996; Cauli et al., 1997; Savic et al., 2001), which suggest that there are differences in the expression of leakage channels as well.

KCNK, a recently discovered family of ion channels, form voltage-independent, potassium-selective channels that have a molecular structure based on four transmembrane, two pore domains (Lesage and Lazdunski, 2000). These channels are expressed by almost every type of neuronal and non-neuronal cell (Goldstein et al., 2001); they regulate resting membrane potential and input resistance, shaping duration and amplitude of action potentials and controlling the gain factor of intrinsic and synaptic currents. When expressed in heterologous expression systems, KCNK channels are modulated by several chemical, physical, and mechanical stimuli such as free proton concentration, local and

Received Feb. 9, 2005; revised Aug. 27, 2005; accepted Aug. 29, 2005

This work was supported by the American Epilepsy Foundation (M.M.). We thank Dr. G. Maccaferri for constructive criticism of this manuscript.

Correspondence should be addressed to Dr. Marco Martina, Department of Physiology, Feinberg School of Medicine, Northwestern University, 303 East Chicago Avenue, Chicago, IL 60611. E-mail: m-martina@northwestern.edu. D0I:10.1523/JNEUROSCI.2454-05.2005

Copyright $\odot 2005$ Society for Neuroscience $\quad$ 0270-6474/05/259162-09\$15.00/0 general anesthetics, and osmotic stress and through a large number of metabolic pathways, including arachidonic acid, G-proteins, and several kinases (Patel and Honoré, 2001).

$\mathrm{pH}$-sensitive leakage potassium channels (TASK) constitute a subtype of KCNK channels that are downregulated by extracellular acidification (Duprat et al., 1997; Leonoudakis et al., 1998; Millar et al., 2000). Several studies have shown TASK channel expression in mammalian brain (for review, see Lesage and Lazdunski, 2000; Goldstein et al., 2001), but less is known about their expression within individual cell types. In situ hybridization and immunohistochemical data show that the brain distribution of TASK channels is uneven and suggest that their expression might differ between interneurons and principal neurons (Talley et al., 2001). The most abundantly expressed of all the KCNK subunits are probably TASK1 and TASK3, which are almost ubiquitous in the CNS (Karschin et al., 2001; Talley et al., 2001).

Our knowledge of the molecular composition of the KCNK channels expressed in the hippocampus is limited, and little is known about the biophysical and pharmacological properties of the leakage conductance of hippocampal neurons. Moreover, the functional significance of the expression of diverse KCNK channels in specific cell populations remains essentially unexplored, although papers addressing the functional impact of KCNK expression in individual cell types have begun to appear (Washburn et al., 2002; Han et al., 2003; Meuth et al., 2003).

A consequence of the $\mathrm{pH}$ sensitivity of TASK channels is their potential role in pathological conditions such as stroke and epi- 
lepsy, in which the extracellular $\mathrm{pH}$ is severely altered. The hippocampus is an area of the brain in which the $\mathrm{pH}$ change induced by ischemia is especially large (LaManna et al., 1992).

In this study, electrophysiological measurements and singlecell reverse transcription (RT)-PCR show that TASK channels expression in hippocampal CA1 pyramidal cells is higher than in horizontal interneurons. This fact could explain the differences in membrane potential and input resistance, as well as the differential sensitivity to anoxia of these cell types (Fryd Johansen et al., 1983).

\section{Materials and Methods}

Hippocampal brain slices. Fourteen- to 23-d-old Long-Evans rats were anesthetized with isoflurane and killed by decapitation. All experiments followed protocols approved by the Northwestern University Center for Comparative Medicine, an Association for Assessment and Accreditation of Laboratory Animal Care accredited facility, and followed guidelines issued by the National Institutes of Health and the Society for Neuroscience.

The brains were quickly removed from the skull in ice-cold artificial CSF (ACSF) containing the following (in $\mathrm{mm}$ ): $125 \mathrm{NaCl}, 25 \mathrm{NaHCO}_{3}$, $2.5 \mathrm{KCl}, 1.25 \mathrm{NaH}_{2} \mathrm{PO}_{4}, 2 \mathrm{CaCl}_{2}, 1 \mathrm{MgCl}_{2}$, and 25 glucose, $\mathrm{pH} 7.4$ (bubbled with $95 \% \mathrm{O}_{2}$ and $5 \% \mathrm{CO}_{2}$ ). Transverse hippocampal slices of 300 $\mu \mathrm{m}$ thickness were cut using a vibroslicer (Dosaka; Ted Pella, Redding, $\mathrm{CA}$ ) and then stored in a solution containing the following (in mM): 87 $\mathrm{NaCl}, 25 \mathrm{NaHCO}_{3}, 2.5 \mathrm{KCl}, 1.25 \mathrm{NaH}_{2} \mathrm{PO}_{4}, 0.5 \mathrm{CaCl}_{2}, 7 \mathrm{MgCl}_{2}, 75$ sucrose, and 25 glucose, $\mathrm{pH} 7.4$ (bubbled with $95 \% \mathrm{O}_{2}$ and $5 \% \mathrm{CO}_{2}$ for $15 \mathrm{~min}$ at $35^{\circ} \mathrm{C}$ and subsequently at room temperature). For the recordings, slices were transferred to a recording chamber continuously superfused with physiological ACSF. When experiments required reducing the $\mathrm{pH}$ values of the bathing solution, the concentration of bicarbonate was lowered to $1 \mathrm{~mm}$ by equiosmolar substitution with $\mathrm{NaCl}$. In some experiments, the $\mathrm{pH}$ was lowered by perfusing the slices with HEPES-buffered ACSF. No differences were apparent when using the two methods, and therefore data have been pooled together. Extracellular alkalinization was obtained by bubbling the ACSF with $100 \%$ oxygen; under this condition, the extracellular $\mathrm{pH}$ was $\sim 8.7$. All experiments were performed at $22-24^{\circ} \mathrm{C}$

Electrophysiological recordings. Pipettes were pulled either from Hilgenberg (Malsfeld, Germany) glass (1406180) or from World Precision Instruments (Sarasota, FL) glass (PG10-165) using a horizontal puller (P97; Sutter Instruments, Novato, CA) and filled with internal solution consisting of the following (in mM): $90 \mathrm{KH}_{2} \mathrm{PO}_{4}, 40 \mathrm{KCl}, 10 \mathrm{NaCl}, 2 \mathrm{MgCl}_{2}, 10$ EGTA, $2 \mathrm{Na}_{2} \mathrm{ATP}, 0.03 \mathrm{NaGTP}$, and 10 HEPES, pH 7.3 with KOH. Tip resistances in working solutions ranged from 2 to $4 \mathrm{M} \Omega$, yielding series resistances of $10-30 \mathrm{M} \Omega$ that were compensated by $35-50 \%$.

Slices were visualized with an Axioskop 2FS (Zeiss, Jena, Germany) upright microscope using infrared differential interference contrast video microscopy (Stuart et al., 1993) with a water-immersion $40 \times$ objective.

Pyramidal cells and interneurons were identified visually on the basis of their location, shape and, after patching, their distinctive firing patterns (Martina et al., 1998; Lien et al., 2002). Whole-cell signals were recorded using either a Multiclamp 700A or one or two (for double recordings) Axopatch 200B amplifiers (Axon Instruments, Union City, CA). Signals were filtered at $10 \mathrm{kHz}$ and sampled at $30 \mathrm{kHz}$. Currents elicited with slow voltage ramps were filtered at $5 \mathrm{kHz}$ and sampled at 10 $\mathrm{kHz}$. Traces presented in the figures represent single sweeps or the average of up to three sweeps.

Bupivacaine stock solution $(50 \mathrm{~mm})$ was prepared in water and stored at $4^{\circ} \mathrm{C}$. Isoflurane $(7.5 \mathrm{~mm})$ was dissolved in oxygenated ACSF immediately before the experiments, kept in a sealed bottle, and applied to the bath solution at a rate of $4-5 \mathrm{ml} / \mathrm{min}$. The concentration reported represents the upper limit of the possible real concentration because it does not account for incomplete solution and potential evaporation.

Solutions containing the final drug concentrations were prepared freshly every day. All chemicals were from Sigma (St. Louis, MO), except tetrodotoxin (TTX) (Alomone Labs, Jerusalem, Israel) and isoflurane (Abbott Laboratories, North Chicago, IL).
Analysis of electrophysiological recordings. The input resistance of the cells was calculated in either current clamp or voltage clamp. In current clamp, it was determined from the voltage response to injection of hyperpolarizing current pulses $(100 \mathrm{pA}, 1 \mathrm{~s})$, measured at the peak of the hyperpolarization. Voltage values were averaged over a $15 \mathrm{~ms}$ time window and divided by the amplitude of the current pulse. In voltage clamp, cells were held at $-55 \mathrm{mV}$, and current responses were elicited with 5 $\mathrm{mV}, 30 \mathrm{~ms}$ steps; the input resistance was then calculated by dividing the amplitude of the voltage step by the amplitude of the current response at the steady state. Because the value of input resistance depends also on the size of the cell, when input resistance values were compared between different cell types (i.e., interneurons and pyramidal cells), we normalized the values by surface area derived from capacitance measurements. These calculations were performed assuming that the specific membrane capacitance is the same for both cell types $\left(0.9 \mu \mathrm{F} / \mathrm{cm}^{2}\right)$ (Gentet et al., 2000).

$I-V$ curves were fit with a standard Goldman-Hodgkin-Katz (Hille, 2001) current equation of the following form:

$$
I_{s}=P_{s} z_{s}^{2} \frac{E F^{2}}{R T} \frac{[S]_{i}-[S]_{o} \exp \left(-z_{s} F E / R T\right)}{1-\exp \left(-z_{s} F E / R T\right)},
$$

where $P$ is the permeability, $[\mathrm{S}]_{\mathrm{i}}$ and $[\mathrm{S}]_{\mathrm{o}}$ are the intracellular and extracellular concentrations of the permeant ion, respectively, $z$ the valence, $F$ the Faraday's constant, $R$ is the gas constant, $E$ is the voltage, and $T$ is the absolute temperature. This function represents the rectification expected for the current flowing through a voltage-independent channel under conditions in which the concentrations of the main permeant ion are different on the two sides of the membrane. For the voltage-clamp analysis of leakage currents, the concentration of extracellular $\mathrm{K}^{+}$was raised from 2.5 to $5 \mathrm{~mm}$ to obtain larger currents at more negative membrane potentials.

Membrane potential values were not corrected for liquid junction potentials ( $\sim 7.5 \mathrm{mV}$, measured using a $3 \mathrm{M} \mathrm{KCl}$ agar bridge); the junction potential difference between the solutions at different $\mathrm{pH}$ was negligible $(\leq 0.4 \mathrm{mV})$ and was not taken into account.

Data obtained from different cell populations were tested using Student's $t$ test for unpaired samples; changes caused by treatments of individual cells were assessed using a paired $t$ test. All data are presented as mean \pm SEM. Error bars in the figures also represent SEM.

Single-cell RT-PCR from slices. Neurons were visually identified and their firing patterns were tested to functionally confirm the morphological identification. Patch pipettes had large tips (resistance in working solution ranging from 0.8 to $1.2 \mathrm{M} \Omega$ ) and were filled with an autoclaved internal solution containing the following (in mM): $140 \mathrm{KCl}, 5 \mathrm{EGTA}$, and 5 HEPES, pH 7.3 with $\mathrm{KOH}$. Neurons were patched and recorded in current clamp, and their cytoplasm was harvested into the patch pipette and expelled into an autoclaved reaction tube containing oligo-dT primer, deoxyribonucleoside triphosphates, ribonuclease inhibitor SUPERasa-in (Ambion, Austin, TX), and BSA. The tubes were incubated at $65^{\circ} \mathrm{C}$ for $5 \mathrm{~min}$ and then placed in ice for at least $1 \mathrm{~min}$. First-strand cDNA was synthesized using SuperScript III kit (Invitrogen, Carlsbad, CA). The RNA template was removed from the cDNA:RNA hybrid by digestion with RNase $\mathrm{H}$ for $20 \mathrm{~min}$ at $37^{\circ} \mathrm{C}$. Subsequently, the cDNA obtained from each cell was divided into several aliquots and amplified by PCR using a programmable thermal cycler (MJ Research, Watertown, MA). Different aliquots were then used with primers selective for different TASK channel and GAD67 cDNA. In an attempt to improve the detection levels, an alternative approach in which primers for a single TASK subunit were used to amplify the entire cDNA obtained from individual cells was attempted on a very limited sample of neurons. In this case, the reverse transcription product was still divided into two different aliquots, but they were then amplified using the same primers. This method, however, did not significantly improve the percentage of cells that resulted positive. The results obtained with the two methods have therefore been pooled together.

To obtain a positive control for the interneurons, in which the percentage of positive cells for the TASK channel family was low, $2 \mu$ l of the cDNA were tested with primers for GAD67. GAD67 was detected in all of the interneurons tested. The primers used were the following: TASK1 
A
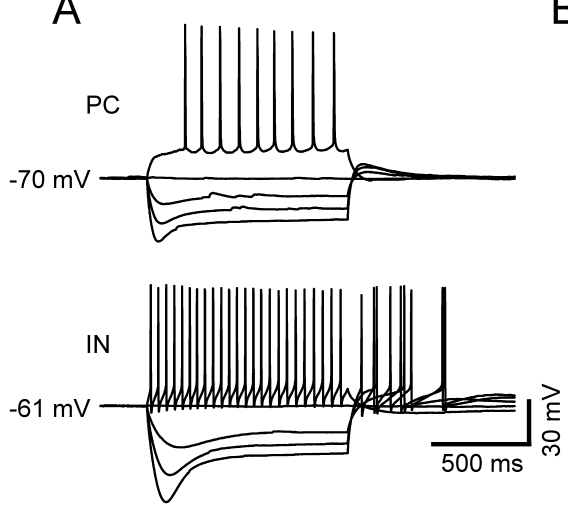

B
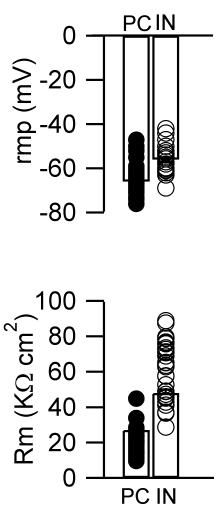

Figure 1. Intrinsic properties of $\mathrm{CA1}$ pyramidal cells $(\mathrm{PC})$ and stratum oriens horizontal interneurons (IN). $A$, Voltage responses to $1 \mathrm{~s}$ current injections (from -300 to $100 \mathrm{pA}, 100 \mathrm{pA}$ steps) in current-clamp recordings. Pyramidal cells (top traces) are characterized by relatively negative resting membrane potential, hyperpolarization-induced sag, and firing of action potentials at low frequency. Interneurons (bottom traces) display less negative resting membrane potential, higher input resistance, prominent sag, and high-frequency firing of action potentials with large afterhyperpolarizations. B, Mean values of resting membrane potential (rmp) and specific membrane resistance $(\mathrm{Rm})$ are significantly different in pyramidal cells and interneurons (78 and 33 cells, respectively; $p<0.01$ ).

(GenBank accession number AF031384): upper primer, CCGCTGCCTTCTCCTACTATG (position 627); lower primer, ACGGTGCTCTGCATCACGCTTCT (position 864); the PCR product size was $260 \mathrm{bp}$; and TASK3 (GenBank accession number AF192366): upper primer, TCCTGACCATGAATACCGATGAA (position 824); lower primer, AGGAAACCGAGTGGACTGTAGC (position 1126); the PCR product size was $324 \mathrm{bp}$. Finally, the primers for GAD67 were the following: upper primer, GTATGACGTCTCCTACGATACAGG (position 1503); and lower primer, AGGAAATCGATGTCAGACTGGGTG (position 1905). PCR product size was 426bp (Tkatch et al., 1998). PCR products were separated by electrophoresis in $1.5 \%$ agarose gels and visualized by staining with ethidium bromide. The identity of PCR products obtained with TASK3 primers in two randomly selected neurons was also confirmed by sequencing.

All PCRs were performed following procedures designed to minimize the chances of cross-contamination. Negative controls for contamination from extraneous and genomic DNA were performed for every batch of neurons. To ensure that genomic DNA did not contribute to the PCR products, control experiments were performed in which neuronal cytoplasm was harvested and processed in the normal manner, except that the reverse transcriptase was omitted. Contaminations from extraneous sources were checked by replacing the cellular template with the background solution. Additional controls to exclude unspecific harvesting of tissue were performed by dragging the pipettes into the slice and taking them out without seal formation and harvesting (Martina et al., 1998).

\section{Results}

Acidification differentially affects the resting potential of pyramidal cells and horizontal interneurons

We compared the intrinsic properties of CA1 pyramidal cells and horizontal interneurons of the stratum oriens, which constitute a relatively homogeneous and easily identifiable interneuronal population (Martina et al., 2000; Maccaferri and Lacaille, 2003). Pyramidal cells and interneurons were selected on the basis of their position, shape, size, and spiking pattern (Fig. 1A). We found that the resting membrane potential of the interneurons was depolarized with respect to that of the pyramidal cells $(-56 \pm 1$ vs $-65 \pm 1 \mathrm{mV} ; 33$ and 78 cells, respectively; $p<0.01)$ (Fig. $1 B$ ). The input resistance was also significantly different between the two cell types, having a value of $403 \pm 20 \mathrm{M} \Omega$ in interneurons and $178 \pm 6 \mathrm{M} \Omega$ in pyramidal cells ( 33 and 78 cells, respectively; $p<0.01$ ). After normalization to surface area (see Materials and Methods), these values corresponded to a specific

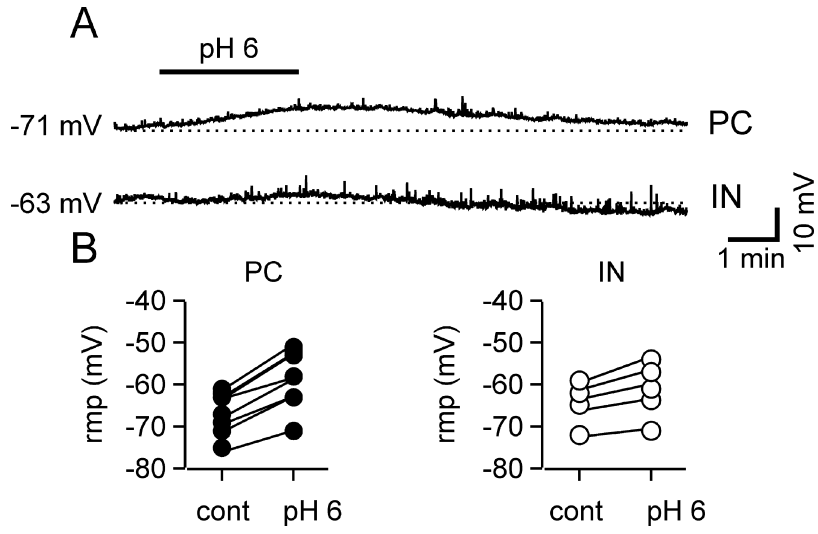

Figure 2. Differential effect of extracellular acidification on pyramidal cells and interneurons. $\boldsymbol{A}$, Simultaneous current-clamp recording from a pyramidal cell (PC, top) and a horizontal interneuron (IN, bottom). A brief bath acidification to $\mathrm{pH} 6.1$ caused a reversible depolarization of the pyramidal cell but only minor effects on this interneuron. $\boldsymbol{B}$, Summary of the acidification effect on the membrane potential of eight pyramidal cells and five interneurons. On average, acidification significantly depolarized both cell types, but the effect was much larger on pyramidal cells (7.1 \pm 0.9 vs $2 \pm 0.7 \mathrm{mV} ; p<0.01)$. Connected points represent measurements from individual cells before and after acidification. rmp, Resting membrane potential; cont, control.

membrane resistance of $48 \pm 3 \mathrm{~K} \Omega / \mathrm{cm}^{2}$ for the interneurons and $27 \pm 1 \mathrm{~K} \Omega / \mathrm{cm}^{2}$ for pyramidal cells $(p<0.01)$ (Fig. $1 B$ ). The fact that interneurons have more depolarized resting potential and higher specific membrane resistance than principal cells suggests that potassium-selective leakage conductances could be expressed at higher density in principal cells and contribute to the observed differences.

TASK channels are probably the leakage channels with the strongest expression in the brain (Talley et al., 2001) and are defined by their sensitivity to extracellular free proton concentration. Therefore, we tested the effects of extracellular acidification on the resting potential and input resistance of the two cell types. Figure $2 \mathrm{~A}$ shows a simultaneous recording from a CA1 pyramidal cell and a stratum oriens horizontal interneuron: when the extracellular $\mathrm{pH}$ was transiently reduced to 6.1 , the pyramidal cell responded with a prompt and reversible depolarization, whereas the interneuron resting potential was almost unaffected. The acidification-induced depolarization was consistently larger in pyramidal cells than in interneurons $(7.1 \pm 0.9$ vs $2.0 \pm 0.7 \mathrm{mV}$; $n=8$ and 5 , respectively; $p<0.01$ ) (Fig. $2 B$ ). Because the depolarization was generated in cells that were at resting potential, it was probably mediated by background conductances. To verify this assumption, we repeated the experiments on pyramidal cells in the presence of $300 \mathrm{~nm} \mathrm{TTX}, 100 \mu \mathrm{M} \mathrm{CdCl}_{2}, 10 \mathrm{~mm}$ tetraethylammonium (TEA), and $1 \mathrm{~mm} \mathrm{CsCl}$ to block voltage-gated sodium, calcium, potassium currents, and $I_{\mathrm{h}}$ and inward rectifier currents, respectively. In some experiments $\mathrm{Cd}^{2+}$ and TEA were omitted; the data obtained in the two conditions were not significantly different and have been pooled together. Under these experimental conditions, the acidification-induced depolarization of pyramidal cells was similar to that in the absence of blockers (the depolarization was $9.3 \pm 1.0 \mathrm{mV}$; five cells; $p<0.05$ ). Extracellular acidification could induce depolarization by opening cationic channels such as acid-sensing ion channels, which are expressed in hippocampal neurons (Baron et al., 2002; Askwith et al., 2004), or by closing background potassium channels. If the blockade of a conductance is involved in pyramidal cell depolarization, it should be paralleled by an increase of the cell input resistance. To verify this hypothesis, we monitored the input resistance of pyramidal neurons while decreasing the extracellular $\mathrm{pH}$ value from $\sim 7.4$ to $\sim 6.1$. Extracellular acidification induced 

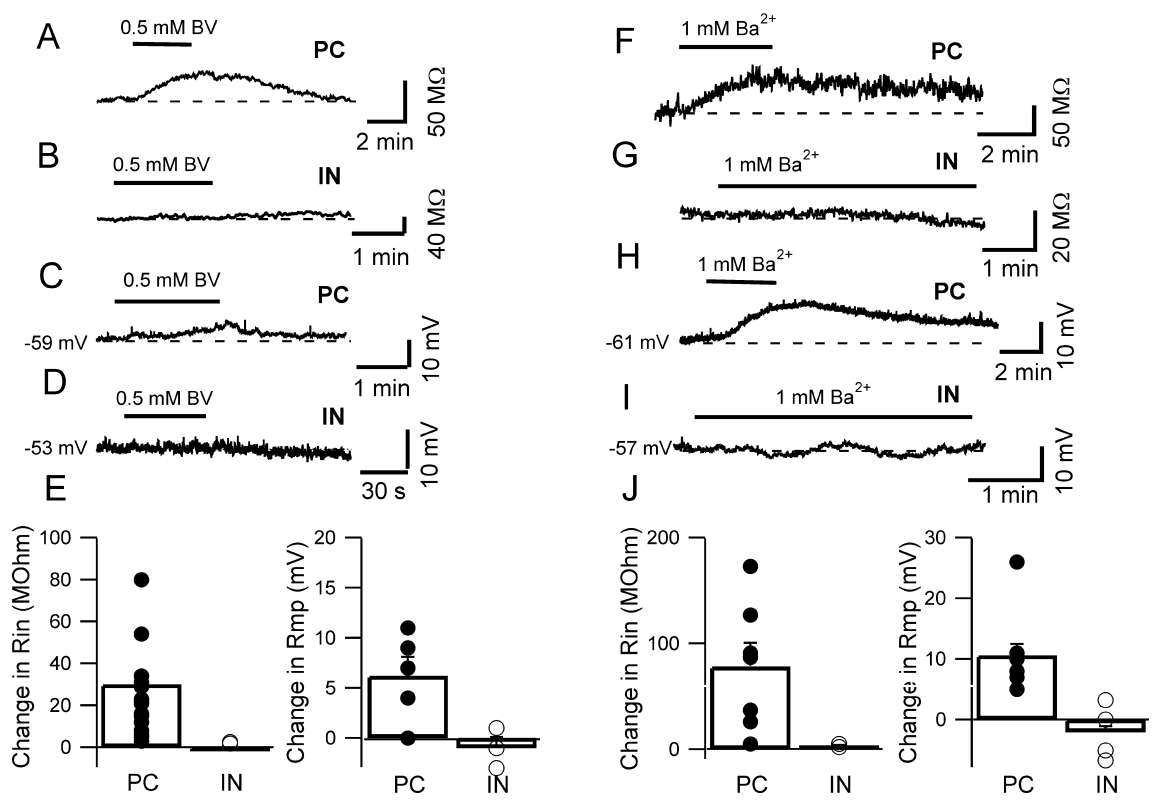

Figure 3. Differential effects of bupivacaine (BV) $(0.5 \mathrm{~mm})$ and barium $(1 \mathrm{~mm})$ on pyramidal cells and interneurons. $\boldsymbol{A}-\boldsymbol{D}$, Bupivacaine increased the input resistance and depolarized pyramidal cells but not interneurons. Time courses of cell input resistance were obtained in voltage clamp by applying short voltage steps $(5 \mathrm{mV}, 30 \mathrm{~ms}$, at $3.3 \mathrm{~Hz})$ from a holding potential of -55 $\mathrm{mV}$, in the presence of voltage-gated channels blockers (see Materials and Methods). $\boldsymbol{E}$, Bar chart summarizing the bupivacaineinduced changes of input resistance (Rin) and membrane potential ( $r m p)$ for the two cell types. $\boldsymbol{F}$-I, Qualitatively similar, but larger, effects were obtained with $1 \mathrm{~mm}$ barium. These results are summarized in $J$.

a significant increase of the input resistance of pyramidal cells $(18 \pm 5 \% ; p<0.05 ; 16$ cells; data not shown) (see Fig. $6 A, B, G, H$ ) that was reversible on restoration of the control $\mathrm{pH}$ value.

\section{TASK-like currents are detectable in pyramidal cells but not in horizontal interneurons}

Our experiments suggest that extracellular acidification affects the membrane potential and input resistance of pyramidal cells through its effects on background potassium conductance. TASK channels have been carefully characterized in heterologous expression systems (Goldstein et al., 2001; Patel and Honoré, 2001); they are insensitive to most of the commonly used potassium channels blockers such as TEA, 4-AP, or dendrotoxins (Lesage, 2003), but they are blocked by external barium and by the local anesthetic bupivacaine (Leonoudakis et al., 1998; Kim et al., 2000; Meadows and Randall, 2001). To characterize the leakage currents of pyramidal cells without risking contamination by $\mathrm{pH}$ sensitive cationic currents, we tested the effects of extracellular application of barium and bupivacaine on membrane potential and input resistance of these neurons. The experiments were performed in the presence of the full mixture of channel blockers described previously. Figure 3 shows that the effects of bupivacaine $(500 \mu \mathrm{M})$ and barium $(1 \mathrm{~mm})$ on the membrane potential and input resistance of hippocampal neurons were cell specific. Bupivacaine increased the input resistance of pyramidal cells $(18 \pm 3 \% ; p<0.05 ; n=19)$ (Fig. $3 A, E)$ and induced a depolarization of their membrane potential $(6.2 \pm 1.9 \mathrm{mV} ; p<0.05 ; n=$ 5) (Fig. 3C,E) but had no significant effect on either the membrane potential or the input resistance of interneurons $(p>0.1$ for both parameters; $n=3$ ) (Fig. $3 B, D, E$ ). Bupivacaine has been shown to be effective on potassium-selective leakage currents at lower concentrations (both on myelinated axons and in brain slice preparations) (Koh et al., 1992; Meuth et al., 2003), and therefore we also tested a lower concentration. At $50 \mu \mathrm{M}$, bupivacaine had similar, although smaller, effects on pyramidal cells, and again no significant effects on interneurons; bupivacaine at $50 \mu \mathrm{M}$ increased the input resistance of pyramidal cells by $15 \pm 3 \%(p<0.05 ; n=5$; data not shown), whereas the input resistance of interneurons was actually slightly decreased $(8 \pm 7 \% ; p>0.1 ; n=3$; data not shown).

Barium (1 mM) had larger effects on pyramidal neurons, causing a $41 \pm 12 \%$ increase of input resistance that was accompanied by a robust depolarization $(10.6 \pm 2.3 \mathrm{mV} ; p<0.05$ for both parameters; eight pyramidal cells) (Fig. $3 F, H, J$ ) but no substantial effects on interneurons. Barium effect on interneurons was limited to a $2.1 \pm 0.2 \%$ change of the input resistance and $2.1 \pm 2.2 \mathrm{mV}$ hyperpolarization of the membrane potential (three and four cells, respectively; $p>0.1$ ) (Fig. $3 G, I, J)$.

\section{Properties of TASK-like currents in pyramidal cells}

To examine the properties of the background currents of pyramidal cells, we performed voltage-clamp experiments and studied the currents obtained by either barium or bupivacaine subtraction. Voltage-gated channels were blocked by the usual mixture of voltage-gated channel blockers and inactivated by holding the cells at $-20 \mathrm{mV} ; 500$ $\mathrm{ms}$ pulses from -120 to $-60 \mathrm{mV}$ in $10 \mathrm{mV}$ steps were then delivered in control conditions and in the presence of either $1 \mathrm{mM}$ barium or $0.5 \mathrm{~mm}$ bupivacaine. The barium-sensitive current, obtained by digital subtraction, had amplitude of $-95 \pm 25 \mathrm{pA}$ at $-120 \mathrm{mV}(n=7)$, had quasi-instantaneous onset, and showed no inactivation during the $500 \mathrm{~ms}$ test pulse (Fig. 4). The $I-V$ plot of the current could be fit by a Goldman-Hodgkin-Katz current equation (Fig. 4C), confirming the voltage independence of this current; its reversal potential was $-78 \pm 4 \mathrm{mV}$, close to the value $(-77 \mathrm{mV})$ predicted by the Nernst equation for a potassiumselective current. To further test the ionic selectivity of this current, we raised the extracellular potassium concentration from 5 to 20 $\mathrm{mM}$; under these conditions, the reversal potential of the current was shifted to $-45 \pm 4 \mathrm{mV}$, in good agreement with the value expected $(-46 \mathrm{mV})$ for a potassium-selective channel (Fig. $4 D)$.

When tested in voltage clamp, bupivacaine $(0.5 \mathrm{~mm})$ blocked $28 \pm 5 \%$ of the leakage current in pyramidal cells $(-70 \pm 27 \mathrm{pA}$ at $-120 \mathrm{mV} ; n=5$ ). The bupivacaine-sensitive current (Fig. 5) had current-voltage relationship and reversal potential similar to those of the barium-sensitive current (Fig. $5 B, C$ ). Interestingly, both of the currents were best fit by the Goldman-Hodgkin-Katz current equation when assuming that the channels are equally permeable to potassium and cesium, which is similar to what was described by Meadows and Randall (2001) for TASK3 homomeric channels expressed in heterologous systems.

The bupivacaine effect on pyramidal cells was smaller than that of barium and similar to that of low external $\mathrm{pH}$; to test whether bupivacaine was acting on the same channels affected by extracellular acidification, we designed an occlusion experiment in which cells were first exposed to extracellular acidification $(\mathrm{pH}$ 6.1 ) and then bupivacaine $(0.5 \mathrm{~mm})$ was added on top of the acidic bathing solution. When applied on top of a $\mathrm{pH} 6.1$ solution, the depolarization induced by bupivacaine was significantly 
A

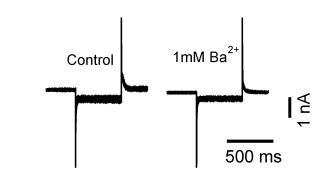

B
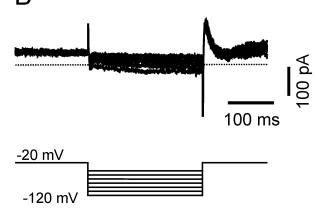

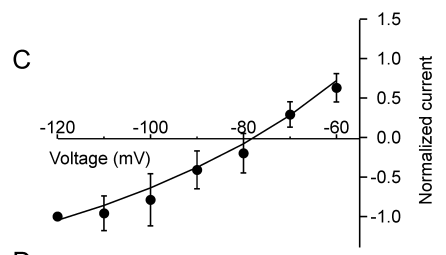

D

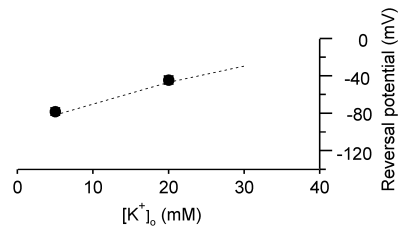

Figure 4. Barium-sensitive $\mathrm{K}^{+}$currents in pyramidal cells. $A$, Voltage-clamp recordings in control conditions (in the presence of blockers of voltage-gated channels; see Materials and Methods) and after extracellular application of $1 \mathrm{~mm}$ barium. $\boldsymbol{B}$, Barium-sensitive current obtained by digital subtraction. Pulse protocol: $500 \mathrm{~ms}$ steps from -60 to $-120 \mathrm{mV}$ in $10 \mathrm{mV}$ increases from a holding potential of $-20 \mathrm{mV}$ (inset). The dotted line represents the zero current level. The outward current at the end of the test pulse was probably mediated by barium-sensitive, TEA-insensitive fast-inactivating $\mathrm{K}^{+}$channels that were deinactivated during the hyperpolarizing voltage pulses. $C, I-V$ curves for barium-sensitive current. Data points were normalized to the amplitude of the current at $-120 \mathrm{mV}$ and fit with the GoldmanHodgkin-Katz current equation (smooth line). The best fit was obtained when the concentration of the extracellular permeant ion was assumed to be $6 \mathrm{~mm}$, which represents the sum of the concentrations of external potassium $(5 \mathrm{~mm}$ ) and cesium $(1 \mathrm{~mm})$. D, Shift of the current reversal potential plotted as a function of extracellular potassium concentration. The dotted line represents the shift predicted by the Nernst equation for a potassium-selective current.

A
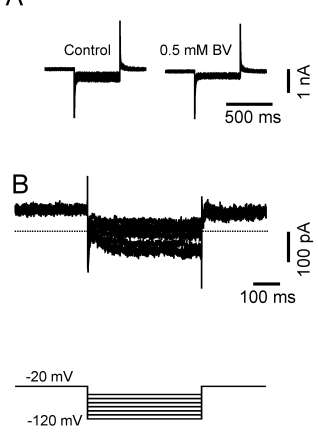

C
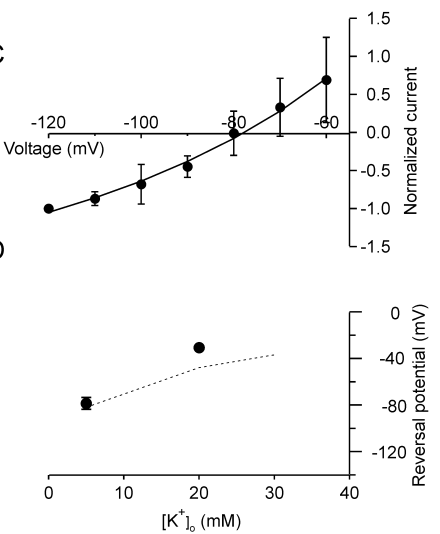

Figure 5. Bupivacaine-sensitive $\mathrm{K}^{+}$currents in pyramidal cells. $A$, Voltage-clamp recordings in control conditions and after perfusion of the slice with $0.5 \mathrm{~mm}$ bupivacaine. $\boldsymbol{B}$, Bupivacaine-sensitive current obtained by digital subtraction. Same voltage protocol as in Figure 4. The dotted line represents the zero current level. C, Normalized I-V curves for bupivacaine-sensitive currents. Data points were normalized to the amplitude of the current at $-120 \mathrm{mV}$ and fit with the Goldman-Hodgkin-Katz current equation (smooth line). The best fit was obtained assuming that the channels are equally permeable to potassium and cesium. $\boldsymbol{D}$, Shift of the current reversal potential plotted as function of the extracellular potassium concentration. The dotted line represents the shift predicted by the Nernst equation for a potassiumselective current.

smaller than in control conditions $(0.8 \pm 0.7 \mathrm{mV}$ increase vs $6.2 \pm 1.9 \mathrm{mV} ; p<0.05 ; n=6$; data not shown). The effect of bupivacaine on the input resistance was also occluded by low extracellular $\mathrm{pH}$ (bupivacaine, when added on top of acidic $\mathrm{pH}$, only increased the input resistance by $2.5 \pm 2 \% ; n=3 ; p>0.1$ ) (Fig. 6A, $B$ ). These experiments suggest that the same channels blocked by bupivacaine were also sensitive to $\mathrm{pH}$ changes, supporting the hypothesis that pyramidal cells express TASK currents. Barium, conversely, could still effectively increase the cell input resistance when applied on top of bupivacaine $(69 \pm 3 \%$
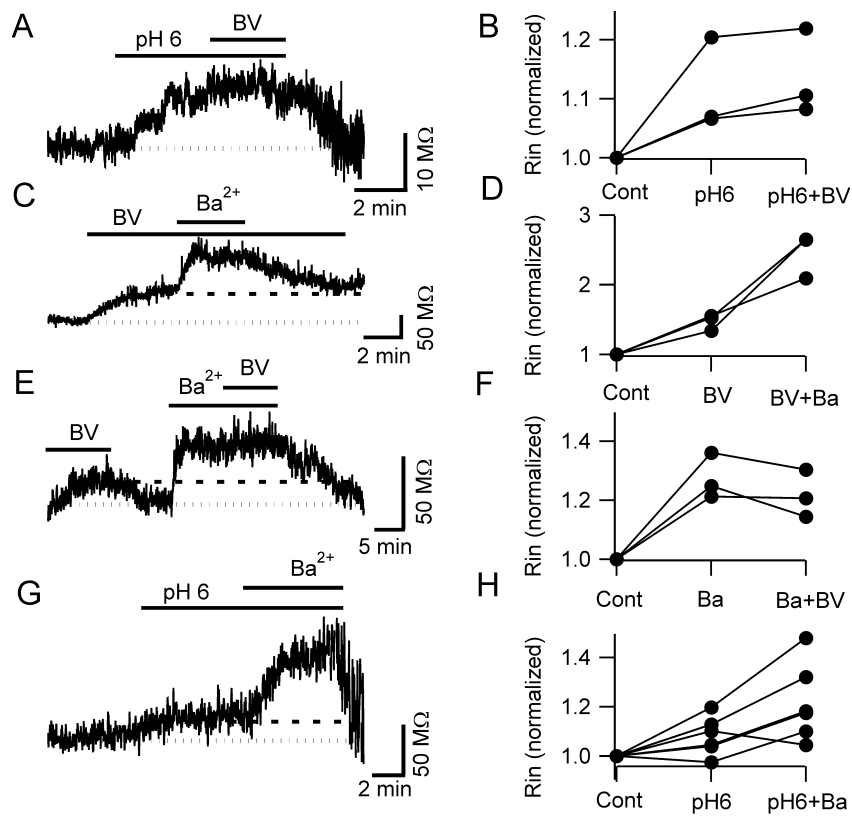

Figure 6. Occlusion experiments suggest the presence of TASK and non-TASK KCNK channels in pyramidal neurons. $\boldsymbol{A}, \boldsymbol{B}$, The effect of bupivacaine (BV) on the cells input resistance was occluded by acidic $\mathrm{pH}$ (dotted line in $\boldsymbol{A}$ represents the baseline value). $\boldsymbol{B}$, Plot of input resistance (Rin) values, in the presence of acidic $\mathrm{pH}$ and acidic $\mathrm{pH}$ plus bupivacaine normalized to those in control condition (Cont). C, D, The effect of barium was not occluded by bupivacaine. After the cells were exposed to bupivacaine, subsequent application of barium (1 mm) caused an additional increase of the input resistance. After barium washout, the input resistance returned to the level induced by bupivacaine alone (dashed line). $\boldsymbol{D}$, Input resistance values (normalized to control) in bupivacaine and bupivacaine plus barium in three cells. $\boldsymbol{E}, \boldsymbol{F}$, In opposition, the increase in input resistance induced by $3 \mathrm{~mm}$ barium completely occluded the effect of bupivacaine; in the trace in $\boldsymbol{E}$, note the positive control for the bupivacaine effect obtained before the occlusion experiment. $\mathbf{G}, \boldsymbol{H}$, Acidic pH could not completely occlude the effect of barium ( $3 \mathrm{~mm}$; 6 pyramidal neurons). All recordings were obtained in the presence of voltage-gated channel blockers.

increase in the three cells tested; $p<0.05$ ) (Fig. 6C,D), suggesting that, although the barium- and the bupivacaine-sensitive currents have similar properties, they could be mediated, at least in part, by different channels. To further explore this subject, we performed an occlusion experiment in which bupivacaine was applied on top of barium. As shown in Figure 6, E and F, barium (3 mM) completely occluded the action of bupivacaine, suggesting that the bupivacaine-sensitive conductance is a subset of the larger barium-sensitive conductance. If so, it could be possible that not all of the barium-sensitive current is sensitive also to $\mathrm{pH}$ changes: to verify this hypothesis, we performed another occlusion experiment in which we first exposed the cells to extracellular acidification ( $\mathrm{pH}$ 6.1) and then applied barium (3 mM) on top (Fig. $6 G, H)$. In this set of experiments, extracellular acidification increased the pyramidal cell input resistance by $9 \pm 4 \%(n=6)$; application of barium on top of $\mathrm{pH} 6.1$ induced an additional increase of the input resistance $(14 \pm 4 \%$ with respect to the value in $\mathrm{pH} 6.1$; $n=6 ; p<0.05$ ), providing additional support to the hypothesis that barium also affects some KCNK channel other than TASK.

\section{Effects of isoflurane and alkaline $\mathrm{pH}$}

TASK channels are known targets for general anesthetics (Lesage and Lazdunski, 2000; Patel and Honoré, 2001); therefore, we studied the effects of isoflurane $(\sim 7.5 \mathrm{~mm})$ on the leakage currents of pyramidal neurons. For these experiments, the extracellular solution contained picrotoxin $(50 \mu \mathrm{M})$ to prevent possible effects of isoflurane on tonic GABA currents. Under these conditions, isoflurane induced a hyperpolarization of the membrane 
A

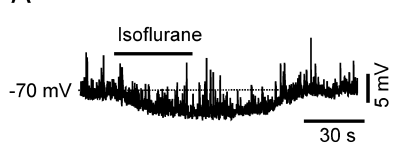

B
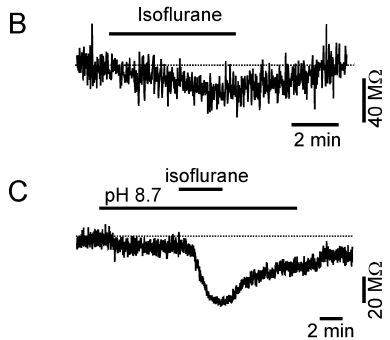

$\mathrm{D}$

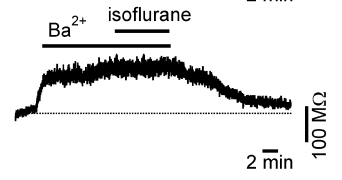

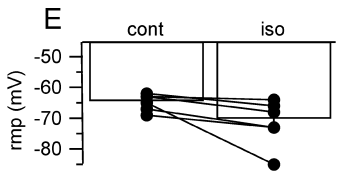
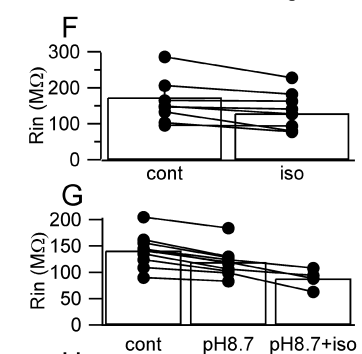

$\mathrm{H}$

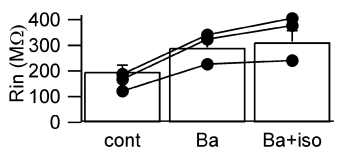

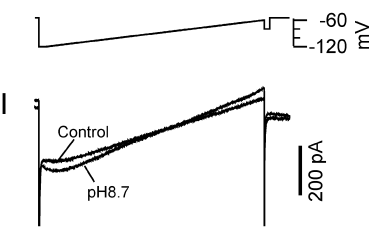
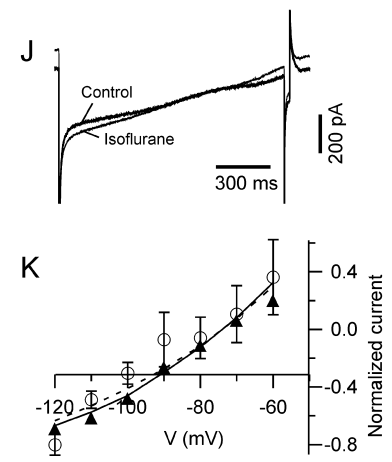

Figure 7. Properties of the alkaline $\mathrm{pH}$ - and isoflurane-sensitive currents of pyramidal cells. $\boldsymbol{A}$, Current-clamp recording showing isoflurane-induced hyperpolarization of a pyramidal neuron. $\boldsymbol{B}$, Isoflurane also induced a decrease of input resistance. $\boldsymbol{C}, \boldsymbol{D}$, Isoflurane-induced decrease in input resistance was not occluded by extracellular alkalinization ( $\boldsymbol{C}$ ) but was blocked by barium (D). $\boldsymbol{E}-\boldsymbol{H}$, Bar charts summarizing the effects illustrated in $\boldsymbol{A}-\boldsymbol{D}$. I, Current elicited by a slow voltage ramp from -120 to $-60 \mathrm{mV}$ ( 50 $\mathrm{mV} / \mathrm{s}$; inset) at pH 7.4 (control) and 8.7. J, Current elicited by the same voltage ramp in the absence (control) and presence ( $\sim 7.5$ $\mathrm{mm}$; see Materials and Methods) of isoflurane. $\boldsymbol{K}, \mathrm{I}-\mathrm{V}$ relationship obtained by digital subtraction, of the $\mathrm{pH} 8.7$-sensitive (open circles; representing the average values from 3 cells) and the isoflurane-sensitive (filled triangles; $n=4$ ) currents. Both currents could be fit with a Goldman-Hodgkin-Katz current equation (the dotted line represent the fit of the pH-sensitive current, the solid line represents the isoflurane-sensitive current).

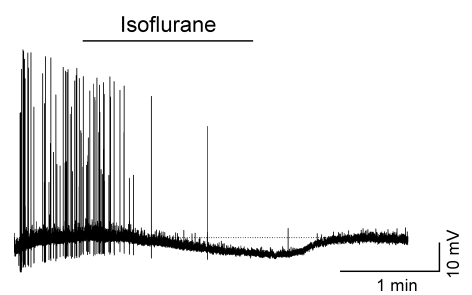

Figure 8. Isoflurane hyperpolarized horizontal interneurons. Voltage response of a horizontal interneuron to the application of isoflurane $(\sim 7.5 \mathrm{~mm})$. The external solution contained picrotoxin $(50 \mu \mathrm{m})$. Isoflurane produced a significant and reversible hyperpolarization of the membrane potential. Similar effects were observed in all four cells tested.

potential in all of the pyramidal neurons tested $(6 \pm 3 \mathrm{mV} ; p<$ $0.05 ; n=6$ ) (Fig. $7 A, E)$. This effect was paralleled by a $15 \pm 7 \%$ decrease of the input resistance $(p<0.05 ; n=8)$ (Fig. $7 B, F)$, supporting the idea that the hyperpolarization was caused by the opening of some channels. Recent studies on expression systems have shown that channels formed by homomeric TASK1, TASK3, and heteromeric TASK1/TASK3 channels can be differentiated by their sensitivity to isoflurane and extracellular $\mathrm{pH}$; in particular, the current recorded at $\mathrm{pH} 8.3$ is more than double that at $\mathrm{pH} 7.3$ for TASK1 homomers, whereas this ratio is very small for TASK3 homomers. TASK1/TASK3 heteromeric channels show an intermediate dependence on pH (Berg et al., 2004; Kang et al., 2004). We tested the effects of extracellular alkalinization on pyramidal neurons in the presence of the usual mix of blockers of voltage-gated channels. When the extracellular $\mathrm{pH}$ was raised from 7.4 to 8.7 , the input resistance dropped by $16 \pm$ $1 \%(n=9 ; p<0.01)$, suggesting that these neurons express also TASK channels different from TASK3 homomers. At the same time, application of isoflurane on top of extracellular alkalinization resulted in an additional reduction of the input resistance, suggesting that either TASK3 homomers or TASK1/TASK3 het- eromers are expressed (Fig. 7C,G). The last question still open was whether the channels opened by isoflurane are the same blocked by barium. To address this question, we first blocked the background conductance of pyramidal neurons with a saturating concentration of barium (3 mM) and then applied isoflurane $(\sim 7.5 \mathrm{~mm})$ in the continuous presence of barium. In these conditions, barium completely blocked the effect of isoflurane, which did not induce any significant change of the input resistance when superfused on top of barium $(p>0.1$; $n=3$ ) (Fig. $7 D, H$ ), indicating the two drugs were acting on the same channels.

Voltage-clamp analysis of the alkaline $\mathrm{pH}$ and of the isoflurane-sensitive currents of pyramidal cells was obtained by digital subtraction of the current obtained with slow $(50 \mathrm{mV} / \mathrm{s})$ voltage ramps in control from the current potentiated by the either alkaline extracellular solution (Fig. $7 I$ ) or the anesthetic (Fig. $7 J$ ). Both of the subtracted currents could be fit with the Goldman-Hodgkin-Katz equation and had reversal potentials of approximately $-90 \mathrm{mV}$, close to that expected for potassium-selective currents under our experimental conditions (Fig. $7 K$ ). Somewhat unexpectedly, isoflurane also hyperpolarized interneurons (7.9 $\pm 2 \mathrm{mV} ; p<0.05$; four cells) (Fig. 8). The molecular targets of this action were not further investigated.

The properties of the leakage currents of pyramidal cells $(\mathrm{pH}-$ sensitive, active at rest, insensitive to most blockers of voltagegated and $\mathrm{GABA}_{\mathrm{A}}$ channels, selective for potassium, blocked by bupivacaine and barium, and potentiated by isoflurane), conversely, closely resemble those of TASK channels and suggest that such channels are expressed in pyramidal cells.

\section{Single-cell RT-PCR analysis of TASK channel subunit transcripts}

With the only exception of TASK2, all TASK subunits are expressed at detectable levels in the brain (Decher et al., 2001; Talley et al., 2001). Of these subunits, TASK5 does not produce functional channels when expressed in heterologous systems (Ashmole et al., 2001; Kim and Gnatenco, 2001), and TASK4 channels are active only at $\mathrm{pH}$ levels considerably more alkaline than physiological and are expressed only at low levels in the brain (Decher et al., 2001). TASK1 and TASK3 are both expressed at high levels in the CNS and have biophysical and pharmacological properties very similar to the currents that we have recorded in pyramidal cells (Kim et al., 2000; Talley et al., 2000). Therefore, we used single-cell RT-PCR to examine the expression of these two subunits in pyramidal cells and in stratum oriens horizontal interneurons.

Pyramidal cells and horizontal interneurons were patched in the slices and recorded electrophysiologically; their mRNA was then harvested into the patch pipette to be used for single-cell PCR (see Materials and Methods). Single-cell RT-PCR analysis revealed interesting differences in the expression profile of TASK1 and TASK3 subunits between pyramidal cells and interneurons (Fig. 9). Whereas the expression of TASK 1 was low and similar in the two cell types (the percentage of cells in which TASK1 mRNA was detected was 11 and $14 \%$ for pyramidal cells 

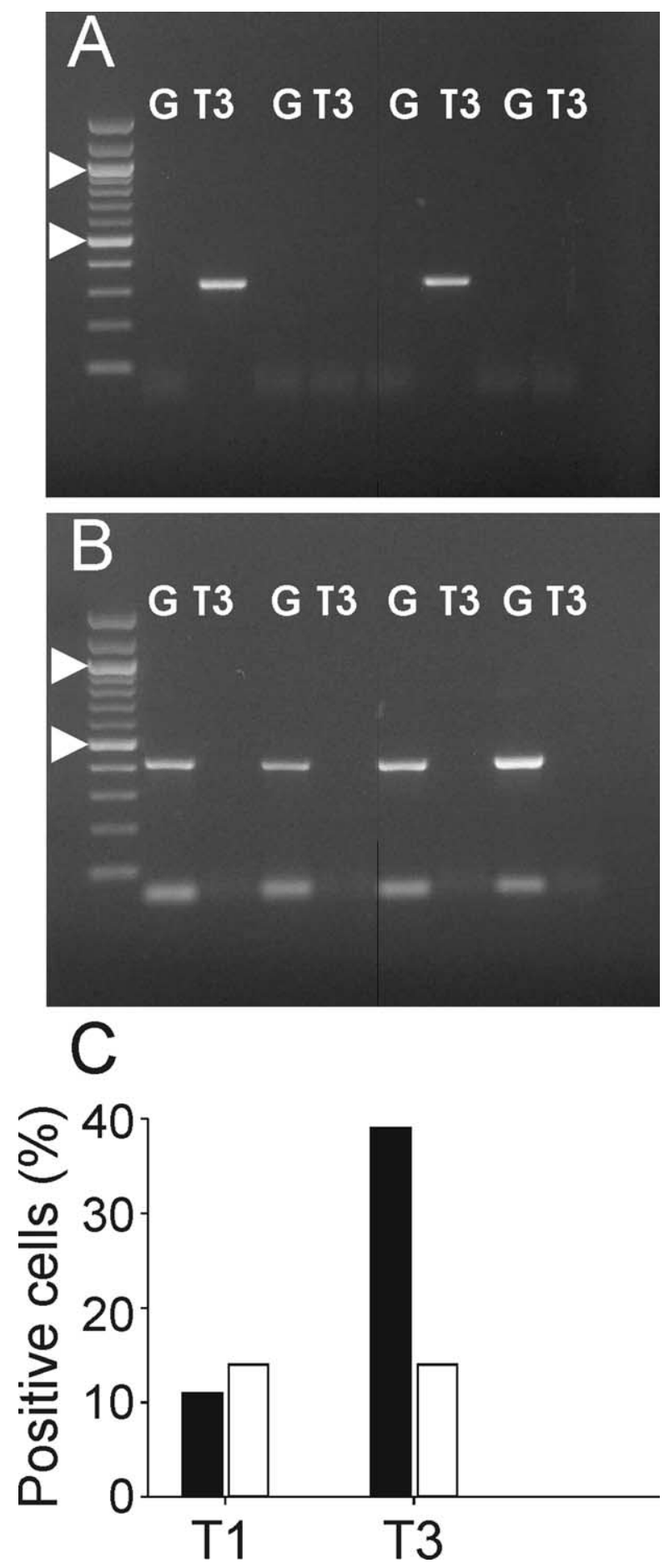

Figure 9. Differential expression of TASK channel mRNA in pyramidal cells and interneurons. $A, B$, Ethidium bromide-stained gels of $P C R$ products obtained with primers for TASK 3 (T3) and GAD67 (G) in pyramidal cells $(\boldsymbol{A})$ and interneurons $(\boldsymbol{B})$. Arrowheads indicate 1000 and $500 \mathrm{bp}$, respectively. $C$, Expression profile of TASK1 and TASK3 subunits in pyramidal cells (solid bars; $n=33$ ) and interneurons (open bars; $n=14$ ).

and interneurons, respectively), expression of TASK3 mRNA was relatively high in principal cells but low in interneurons (39 vs $14 \% ; n=33$ and 14 , respectively). To exclude that the lower detection level obtained in interneurons was attributable to technical problems in any stage of the process, $2 \mu \mathrm{l}$ of the cDNA were routinely used to test the expression of GAD67. All of the interneurons were GAD67 positive, excluding unspecific technical problems.

\section{Discussion}

\section{Pyramidal cells express TASK channels}

The currents recorded in CA1 pyramidal cells closely resembled those mediated by recombinant TASK channels expressed in heterologous systems (Goldstein et al., 2001; Patel and Honoré, 2001). They had relatively small size ( $\sim 25 \mathrm{pA}$ at $-70 \mathrm{mV}, \mathrm{pH} 7.4)$ comparable with that reported for native neuronal TASK currents recorded in similar ionic conditions (Meuth et al., 2003). Among the TASK channels subtypes identified so far, only TASK 2 is not expressed in the brain (Talley et al., 2001). Of the other subunits, TASK5 does not encode for functional channels (Ashmole et al., 2001; Kim and Gnatenco, 2001), and TASK4 is probably not conductive at physiological pH (Decher et al., 2001). These considerations suggest that TASK1 and TASK3 mediate most of the $\mathrm{pH}$-sensitive potassium current in hippocampal pyramidal cells. Similarly to what was reported in the literature for TASK1 and TASK3 channels (Leonoudakis et al., 1998; Talley et al., 2000; Meadows and Randall, 2001), the $I-V$ relationship of this current could be fit with the Goldman-Hodgkin-Katz current equation, revealing the lack of intrinsic voltage dependence.

The native leakage current in CA1 pyramidal cells was blocked by bupivacaine and extracellular barium at concentrations comparable to those reported for homomeric TASK1 and TASK3 channels (Leonoudakis et al., 1998; Kim et al., 2000) and potentiated by isoflurane; this potentiation was completely blocked by extracellular barium, supporting the idea that both were acting on the same channels. Because isoflurane has been shown to potentiate both TASK3 homomers and TASK1/TASK3 heteromers, but not TASK1 homomeric channels (Berg et al., 2004), the isoflurane potentiation could suggest that TASK1 homomers are unlikely to contribute a major component of the current. Conversely, the effect of extracellular alkalinization suggests the presence of channels other than TASK3 homomers in pyramidal cells membrane (Berg et al., 2004; Kang et al., 2004). Finally, the lack of occlusion of the barium effect by either acidic $\mathrm{pH}$ or bupivacaine suggests that, in addition to TASK, other types of bariumsensitive KCNK channels could contribute to the leakage current of pyramidal cells.

Single-cell PCR analysis confirmed the expression of both TASK3 and, at lower levels, TASK1 subunits in these cells suggesting that, similar to what reported for motoneurons (Berg et al., 2004), they could combine to form also heteromeric channels. In conclusion, it is likely that an important share of the potassium background conductance of pyramidal cells is mediated by TASK1 and TASK 3 subunits, which could form both homomeric and heteromeric channels. Nevertheless, other KCNK subunits, such as TREK (TWIK-related $\mathrm{K}^{+}$channel) and TWIK (weakly inwardly rectifying $\mathrm{K}^{+}$channel), whose expression has been reported in hippocampal tissue (Talley et al., 2001), could also contribute to the leakage current of pyramidal neurons as suggested by the fact that barium had additional effects that could not be occluded by either acidic $\mathrm{pH}$ or bupivacaine.

\section{Correlation between electrophysiological and PCR data}

The low detection levels of TASK mRNA in interneurons fit nicely with the electrophysiological recordings. In pyramidal cells, however, the functional data suggest that TASK mRNA is present in all the neurons, whereas it was detected in only $~ 50 \%$ of the cells. This discrepancy could arise from different factors. First, the small size of the current (the bupivacaine-sensitive current was $\sim 70 \mathrm{pA}$ at $-120 \mathrm{mV}$ in whole cell) suggests that the number of channels present in these cells is considerably lower than that of voltage-gated channels that are reliably detected us- 
ing slice single-cell RT-PCR (Martina et al., 1998; Lien et al., 2002). Second, because it is imperative to keep a perfect seal during and after the harvesting to prevent contamination from extracellular mRNA, the size of the pipette cannot exceed 0.9-1.1 $\mathrm{M} \Omega$ (in $140 \mathrm{~mm} \mathrm{KCl}$ ). As a consequence, there is a limit to the amount of material harvested. In particular, it is impossible to harvest dendritic mRNA. It is, however, known that some mRNAs, including some encoding for ion channels, are localized in the dendrites (Crino and Eberwine, 1996; Racca et al., 1997), and it is possible that this is true also for TASK mRNA. Finally, we limited our PCR to 45 cycles to prevent amplification of genomic material. It is possible that increasing the number of cycles could result in higher detection levels.

\section{Functional implication of TASK channels expression in hippocampal neurons}

An intriguing hypothesis concerns the potential role of $\mathrm{KCNK}$ channels in regulating spontaneous firing. It has been suggested that all neurons are endowed with an intrinsic propensity to pacemaking that depends on the biophysical properties of voltagegated sodium channels (Taddese and Bean, 2002), yet, most of the brain neurons, including CA1 pyramidal cells, are not intrinsically firing. High expression levels of KCNK channels might then silence cells that would otherwise fire spontaneously. Some hippocampal interneurons are spontaneous pacemakers (Fricker et al., 1999), and it is tempting to suggest that this property could be linked to a lower expression of KCNK channels; that KCNK channels have important influence on firing patterns has been shown in other cell types, such as thalamocortical neurons, in which the block of a leakage conductance is sufficient to transform the firing mode from bursting to tonic (Meuth et al., 2003).

The modulation of leakage conductance constitutes a finely tunable mechanism of regulating the input/output relationship of the neurons. Apart from changes in pH, TASK channels are modulated by an uncommonly vast array of substances. Native TASK1 channels are modulated by muscarine (Millar et al., 2000), as well as by serotonin, norepinephrine, substance P, and thyrotropin-releasing hormone (Talley et al., 2000). It is therefore possible that the resting conductance responsible for the muscarine-induced depolarization of CA1 pyramidal cells (Benardo and Prince, 1982; Madison et al., 1987) could be mediated by TASK channels. Modulation of TASK channels by group I metabotropic glutamate receptors (Chemin et al., 2003) could also mediate some of the effects of these receptors on hippocampal cell excitability (Mannaioni et al., 2001; Kullmann and Semyanov, 2002; Losonczy et al., 2002).

\section{Contrasting effects of TASK blockers and isoflurane on interneurons}

Neither bupivacaine nor barium had significant effects on the membrane potential and the input resistance of interneurons, and the detection of TASK channel mRNA was less frequent in these cells. Isoflurane, conversely, did hyperpolarize interneurons. One possible explanation for these observations is that interneurons consistently express TASK channels similar to those of pyramidal cells, although at low level. Because both TASK1 and TASK 3 channels have low open probability (Han et al., 2003), the combination of these two factors would result in a current undetectable in resting conditions but discernible when activated by isoflurane. Alternatively, it is possible that, in interneurons, the molecular composition of TASK channels is different than in pyramidal cells; the channels expressed by interneurons are probably not TASK1 homomers, which are not potentiated by isoflu- rane (Berg et al., 2004). However, it has been shown recently that TASK1/TASK3 heteromers (Kang et al., 2004) are present in native neuronal channels (Berg et al., 2004). These heteromers have properties different from those of homomeric TASK1 and TASK3; in particular, TASK1/TASK3 heteromers are sensitive to isoflurane potentiation but have $\mathrm{pH}$ sensitivity intermediate between TASK3 (whose activation curve is almost saturated at $\mathrm{pH}$ 7.4) and TASK1, which have extremely low open probability at physiological pH (Han et al., 2003; Berg et al., 2004). Such heteromers would therefore be almost undetectable in control conditions but sensitive to isoflurane activation. Finally, it is also possible that, in interneurons, isoflurane affects leakage channels different from TASK. Several KCNK channels share with TASK the sensitivity to general anesthetics; TREK-1 and TREK-2, which are both expressed in the CNS (Fink et al., 1996; Bang et al., 2000; Talley et al., 2001), are potentiated by general anesthetics but have lower sensitivity to barium and bupivacaine than TASK (Lesage and Lazdunski, 2000; Patel and Honoré, 2001) (but see Fink et al., 1996). The results obtained in horizontal interneurons could therefore suggest the expression of TREK-like channels in these cells.

\section{TASK channels and ischemic damage}

Hippocampal pyramidal cells are particularly sensitive to anoxia (Fryd Johansen et al., 1983). After an ischemic episode, CA1 pyramidal cells die quickly but horizontal interneurons survive (Blasco-Ibanez and Freund, 1995; Bering et al., 1997). Our data suggest that the interneuron resistance to ischemic damage could be related to a lower expression level of TASK currents. Conversely, the molecular machinery responsible for the ischemic damage in pyramidal cells could involve the TASK channels response to the extracellular acidification that ensues from an ischemic event. Closing of a background conductance would cause a direct cell depolarization, which could in turn activate voltagedependent conductances and finally lead to cytotoxic calcium entry. Interestingly, a common effect of neuroprotective substances such as volatile anesthetics and polyunsaturated fatty acids [which have been shown to prevent neuronal death in animal models of ischemia (Lauritzen et al., 2000)] is their action on potassium-selective leakage channels. In acute ischemic damage, the involvement of TASK channels would therefore differ substantially from their role in apoptosis of cerebellar granule cells, in which it appears that the opening, not the closing, of TASK channels induces cell death (Lauritzen et al., 2003).

\section{References}

Ashmole I, Goodwin PA, Stanfield PR (2001) TASK-5, a novel member of the tandem pore $\mathrm{K}^{+}$channel family. Pflügers Arch 442:828-833.

Askwith CC, Wemmie JA, Price MP, Rokhlina T, Welsh MJ (2004) Acidsensing ion channel 2 (ASIC2) modulates ASIC1 $\mathrm{H}^{+}$-activated currents in hippocampal neurons. J Biol Chem 279:18296-18305.

Bang H, Kim Y, Kim D (2000) TREK-2, a new member of the mechanosensitive tandem-pore $\mathrm{K}^{+}$channel family. J Biol Chem 275:17412-17419.

Baron A, Waldmann R, Lazdunski M (2002) ASIC-like, proton-activated currents in rat hippocampal neurons. J Physiol (Lond) 539:485-494.

Benardo LS, Prince DA (1982) Cholinergic excitation of mammalian hippocampal pyramidal cells. Brain Res 249:315-331.

Berg AP, Talley EM, Manger JP, Bayliss DA (2004) Motoneurons express heteromeric TWIK-related acid-sensitive $\mathrm{K}^{+}$(TASK) channels containing TASK-1 (KCNK3) and TASK-3 (KCNK9) subunits. J Neurosci 24:6693-6702.

Bering R, Draguhn A, Diemer NH, Johansen FF (1997) Ischemia changes the coexpression of somatostatin and neuropeptide $\mathrm{Y}$ in hippocampal interneurons. Exp Brain Res 115:423-429.

Blasco-Ibanez JM, Freund TF (1995) Synaptic input of horizontal interneurons in stratum oriens of the hippocampal CA1 subfield: structural basis of feed-back activation. Eur J Neurosci 7:2170-2180. 
Cauli B, Audinat E, Lambolez B, Angulo MC, Ropert N, Tsuzuki K, Hestrin S, Rossier J (1997) Molecular and physiological diversity of cortical nonpyramidal cells. J Neurosci 17:3894-3906.

Chemin J, Girard C, Duprat F, Lesage F, Romey G, Lazdunski M (2003) Mechanisms underlying excitatory effects of group I metabotropic glutamate receptors via inhibition of $2 \mathrm{P}$ domain $\mathrm{K}^{+}$channels. EMBO J 22:5403-5411.

Crino PB, Eberwine J (1996) Molecular characterization of the dendritic growth cone: regulated mRNA transport and local protein synthesis. Neuron 17:1173-1187.

Decher N, Maier M, Dittrich W, Gassenhuber J, Brüggemann A, Busch AE, Steinmeyer K (2001) Characterization of TASK-4, a novel member of the $\mathrm{pH}$-sensitive, two-pore domain potassium channels family. FEBS Lett 492:84-89.

Duprat F, Lesage F, Fink M, Reyes R, Heurteaux C, Lazdunski M (1997) TASK, a human background $\mathrm{K}^{+}$channel to sense external $\mathrm{pH}$ variations near physiological pH. EMBO J 16:5464-5471.

Fink M, Duprat F, Lesage F, Reyes R, Romey G, Heurteaux C, Lazdunski M (1996) Cloning, functional expression and brain localization of a novel unconventional outward rectifier $\mathrm{K}^{+}$channel. EMBO J 15:6854-6862.

Fricker D, Verheugen JA, Miles R (1999) Cell-attached measurements of the firing threshold of rat hippocampal neurones. J Physiol (Lond) 517:791-804.

Fryd Johansen F, Balslev Jorgensen M, Diemer NH (1983) Resistance of hippocampal CA-1 interneurons to 20 min of transient cerebral ischemia in the rat. Acta Neuropathol (Berl) 61:135-140.

Geiger JR, Melcher T, Koh DS, Sakmann B, Seeburg PH, Jonas P, Monyer H (1995) Relative abundance of subunit mRNAs determines gating and $\mathrm{Ca}^{2+}$ permeability of AMPA receptors in principal neurons and interneurons in rat CNS. Neuron 15:193-204.

Gentet LJ, Stuart GJ, Clements JD (2000) Direct measurement of specific membrane capacitance in neurons. Biophys J 79:314-320.

Goldstein S, Bockenhauer D, O'Kelly I, Zilberger N (2001) Potassium leak channels and the KCNK family of two-P-domain subunits. Nat Rev Neurosci 2:175-184.

Han J, Gnatenco C, Sladek CD, Kim D (2003) Background and tandempore potassium channels in magnocellular neurosecretory cells of the rat supraoptic nucleus. J Physiol (Lond) 546:625-639.

Hille B (2001) Ionic channels of excitable membranes. Sunderland, MA: Sinauer.

Kang D, Han J, Talley EM, Bayliss DA, Kim D (2004) Functional expression of TASK-1/TASK-3 heteromers in cerebellar granule cells. J Physiol (Lond) 554:64-77.

Karschin C, Wischmeyer E, Preisig-Müller R, Rajan S, Derst C, Grzeschik K, daut J, Karschin A (2001) Expression pattern in brain of TASK-1, TASK-3 and a tandem pore domain $\mathrm{K}^{+}$channel subunit, TASK-5, associated with the central auditory nervous system. Mol Cell Neurosci 18:632-648.

Kim D, Gnatenco C (2001) TASK-5, a new member of the tandem-pore $\mathrm{K}^{+}$ channel family. Biochem Biophys Res Commun 284:923-930.

Kim Y, Bang H, Kim D (2000) TASK-3, a new member of the tandem pore $\mathrm{K}^{+}$channel family. J Biol Chem 275:9340-9347.

Koh DS, Jonas P, Brau ME, Vogel W (1992) A TEA-insensitive flickering potassium channel active around the resting potential in myelinated nerve. J Membr Biol 130:149-162.

Kullmann DM, Semyanov A (2002) Glutamatergic modulation of GABAergic signaling among hippocampal interneurons: novel mechanisms regulating hippocampal excitability. Epilepsia 43 [Suppl 5]:174-178.

LaManna JC, Griffith JK, Cordisco BR, Lin CW, Lust WD (1992) Intracellular $\mathrm{pH}$ in rat brain in vivo and in brain slices. Can J Pysiol Pharmacol 70:S69-S77.

Lauritzen I, Blondeau N, Heurteaux C, Widmann C, Romey G, Lazdunski M (2000) Polyunsaturated fatty acids are potent neuroprotectors. EMBO J 19:1784-1793.

Lauritzen I, Zanzouri M, Honore E, Duprat F, Ehrengruber MU, Lazdunski M, Patel AJ (2003) $\mathrm{K}^{+}$-dependent cerebellar granule neuron apoptosis. Role of task leak $\mathrm{K}^{+}$channels. J Biol Chem 278:32068-32076.

Leonoudakis D, Gray AT, Winegar BD, Kindler CH, Harada M, Taylor DM, Chavez RA, Forsayeth JR, Yost CS (1998) An open rectifier potassium channel with two pore domains in tandem cloned from rat cerebellum. J Neurosci 18:868-877.
Lesage F (2003) Pharmacology of neuronal background potassium channels. Neuropharmacology 44:1-7.

Lesage F, Lazdunski M (2000) Molecular and functional properties of twopore-domain potassium channels. Am J Physiol 279:F793-F801.

Lien CC, Martina M, Schultz JH, Ehmke H, Jonas P (2002) Gating, modulation and subunit composition of voltage-gated $\mathrm{K}^{+}$channels in dendritic inhibitory interneurones of rat hippocampus. J Physiol (Lond) 538:405-419.

Losonczy A, Zhang L, Shigemoto R, Somogyi P, Nusser Z (2002) Cell type dependence and variability in the short-term plasticity of EPSCs in identified mouse hippocampal interneurones. J Physiol (Lond) 542:193-210.

Maccaferri G, Lacaille JC (2003) Interneuron Diversity series: hippocampal interneuron classifications-making things as simple as possible, not simpler. Trends Neurosci 26:564-571.

Madison DV, Lancaster B, Nicoll RA (1987) Voltage clamp analysis of cholinergic action in the hippocampus. J Neurosci 7:733-741.

Mannaioni G, Marino MJ, Valenti O, Traynelis SF, Conn PJ (2001) Metabotropic glutamate receptors 1 and 5 differentially regulate CA1 pyramidal cell function. J Neurosci 21:5925-5934.

Martina M, Jonas P (1997) Functional differences in $\mathrm{Na}^{+}$channel gating between fast-spiking interneurones and principal neurones of rat hippocampus. J Physiol (Lond) 505:593-603.

Martina M, Schultz JH, Ehmke H, Monyer H, Jonas P (1998) Functional and molecular differences between voltage-gated $\mathrm{K}^{+}$channels of fastspiking interneurons and pyramidal neurons of rat hippocampus. J Neurosci 18:8111-8125.

Martina M, Vida I, Jonas P (2000) Distal initiation and active propagation of action potentials in interneuron dendrites. Science 287:295-300.

Meadows HJ, Randall AD (2001) Functional characterisation of human TASK-3, an acid-sensitive two-pore domain potassium channels. Neuropharmacology 40:551-559.

Meuth SG, Budde T, Kanyshkova T, Broicher T, Munsch T, Pape HC (2003) Contribution of TWIK-related acid-sensitive channel 1 (TASK1) and TASK3 channels to the control of activity modes in thalamocortical neurons. J Neurosci 23:6460-6469.

Millar JA, Barratt L, Southan AP, Page KM, Fyffe RE, Robertson B, Mathie A (2000) A functional role for the two-pore domain potassium channel TASK-1 in cerebellar granule neurons. Proc Natl Acad Sci USA 97:3614-3618.

Morin F, Beaulieu C, Lacaille JC (1996) Membrane properties and synaptic currents evoked in CA1 interneuron subtypes in rat hippocampal slices. J Neurophysiol 76:1-16.

Patel A, Honoré E (2001) Properties and modulation of mammalian 2P domain $\mathrm{K}^{+}$channels. Trends Neurosci 24:339-346.

Racca C, Gardiol A, Triller A (1997) Dendritic and postsynaptic localizations of glycine receptor alpha subunit mRNAs. J Neurosci 17:1691-1700.

Savic N, Pedarzani P, Sciancalepore M (2001) Medium afterhyperpolarization and firing pattern modulation in interneurons of stratum radiatum in the CA3 hippocampal region. J Neurophysiol 85:1986-1997.

Sperk G, Schwarzer C, Tsunashima K, Fuchs K, Sieghart W (1997) GABA(A) receptor subunits in the rat hippocampus I: immunocytochemical distribution of 13 subunits. Neuroscience 80:987-1000.

Stuart GJ, Dodt HU, Sakmann B (1993) Patch-clamp recordings from the soma and dendrites of neurons in brain slices using infrared video microscopy. Pflügers Arch 423:511-518.

Taddese A, Bean BP (2002) Subthreshold sodium current from rapidly inactivating sodium channels drives spontaneous firing of tuberomammillary neurons. Neuron 33:587-600.

Talley EM, Lei Q, Sirois JE, Bayliss DA (2000) TASK-1, a two-pore domain $\mathrm{K}^{+}$channel, is modulated by multiple neurotransmitters in motoneurons. Neuron 25:399-410.

Talley EM, Solórzano G, Lei Q, Kim D, Bayliss DA (2001) CNS distribution of members of the two-pore-domain (KCNK) potassium channel family. J Neurosci 21:7491-7505.

Tkatch T, Baranauskas G, Surmeier DJ (1998) Basal forebrain neurons adjacent to the globus pallidus co-express GABAergic and cholinergic marker mRNAs. NeuroReport 19:1935-1939.

Washburn CP, Sirois JE, Talley EM, Guyenet PG, Bayliss DA (2002) Serotonergic raphe neurons express TASK channel transcripts and a TASK-like $\mathrm{pH}$ - and halothane-sensitive $\mathrm{K}^{+}$conductance. J Neurosci 22: $1256-1265$. 